\title{
PENGARUH BENTUK DAN RASIO KELANGSINGAN PADA TIANG PANCANG YANG DIBEBANI LATERAL
}

\author{
Andrias Suhendra Nugraha, Poppy Chaerani Mulyadi \\ Jurusan Teknik Sipil, Universitas Kristen Maranatha \\ Jalan Prof. drg. Suria Sumatri, MPH., no.65 Bandung, 40164 \\ Email: andrias.sn@eng.maranatha.edu_chaeranipm@gmail.com
}

\begin{abstract}
ABSTRAK
Tiang pancang adalah salah satu jenis pondasi dalam (deep foundation). Pondasi tiang pancang berfungsi untuk meneruskan beban-beban yang bekerja pada suatu struktur ke dalam tanah. Kedalaman pemancangan tiang bergantung pada besarnya beban kerja (working load), jenis tanah, dan spesifikasi tiang yang digunakan. Pada penelitian ini bentuk tiang pancang yang dianalisis adalah bentuk dengan penampang melintang (cross section) segiempat dengan dimensi $0.35 \mathrm{mx}$ $0.35 \mathrm{~m}$ dan lingkaran dengan diameter $0.35 \mathrm{~m}$. Panjang tiang pancang yang dianalisis adalah 7.0 $\mathrm{m}, 10.0 \mathrm{~m}$ dan $15.0 \mathrm{~m}$. Jenis tanah yang ditinjau adalah tanah non-kohesif ; loose sand, medium sand dan dense sand. Hasil analisis menunjukkan bahwa kapasitas lateral tiang pancang beton bentuk persegi lebih besar dibandingan dengan kapasitas lateral tiang pancang beton bentuk lingkaran dengan perbandingan $17.61 \%$ untuk kondisi pemancangan pada tanah loose sand, 13.41 $\%$ untuk kondisi pemancangan pada tanah medium sand, $23.24 \%$ untuk kondisi pemancangan pada tanah dense sand. Perubahan nilai rasio kelangsingan, $\mathrm{L} / \mathrm{d}$ tidak mempengaruhi besarnya kapasitas lateral tiang pancang baik untuk tiang persegi maupun tiang lingkaran. Penurunan nilai rasio kelangsingan, L/d akan memperkecil nilai defleksi lateral pada kepala tiang baik untuk tiang persegi maupun tiang lingkaran
\end{abstract}

Kata kunci: Tiang pancang, rasio kelangsingan, kapasitas lateral, defleksi lateral.

\begin{abstract}
Driven pile classified as deep foundation. The function of driven pile is to transfer loads of a structure into the ground. The depth of driven pile depends on working loads, type of soils, and pile specifications. This research analyzed the square pile shape of concrete driven pile with the dimension $0.35 \mathrm{~m} \times 0.35 \mathrm{~m}$ and the circle pile shape of concrete driven pile with the diameter of $0.35 \mathrm{~m}$. Length of driven concrete pile are $7.0 \mathrm{~m}, 10.0 \mathrm{~m}$, and $15.0 \mathrm{~m}$. Type of non-cohesive soils which analyzed in this research are loose sand, medium sand and dense sand ..The analysis showed that the lateral capacity of concrete piles with square pile shape larger than lateral capacity of concrete pile with circular pile shape with ratio as follows; $17.61 \%$ which driven into loose sand, $13.41 \%$ which driven in medium sand, $23.24 \%$ which driven into dense sand. Changes in the value of the slenderness ratio, $L / d$ did not affect the amount of lateral capacity of driven piles either square pile shape or circular pile shape. Decrease of slenderness ratio, $L / d$ would reduce the value of the lateral deflection of the pile head either square pile shape or circular pile shape
\end{abstract}

Keyword: driven pile, slenderness ratio, lateral capacity, lateral deflection,

\section{PENDAHULUAN}

Tiang pancang adalah salah satu jenis pondasi dalam (deep foundation). Fungsi dari pondasi tiang pancang adalah untuk meneruskan beban-beban yang bekerja pada struktur atas ke dalam tanah. Kedalaman pemancangan tiang diantaranya bergantung pada besarnya beban kerja (working load), jenis tanah, dan spesifikasi tiang yang digunakan. 
Bentuk penampang melintang (cross section) tiang pancang beton bervariasi, diantarnya adalah ; lingkaran, segiempat, segitiga, spun pile, dan lain-lain. Kedalaman tiang, $\mathrm{L}$ dan diameter/lebar tiang, $\mathrm{d}$ serta rasio kelangsingan, $\mathrm{L} / \mathrm{d}$ (slenderness ratio) akan mempengaruhi perilaku tiang yang dibebani lateral. Pada penelitian ini, bentuk tiang dan rasio kelangsingan akan dianalisis pengaruhnya terhadap kapasitas lateral tiang dan defleksi pada tiang pancang beton yang dibebani lateral dan dipancang pada tanah nonkohesif ; pasir (sand) homogen.

\subsection{TUJUAN PENELITIAN}

Tujuan penelitian adalah untuk melakukan analisis pengaruh dari bentuk dan rasio kelangsingan tiang terhadap kapasitas lateral tiang dan defleksi tiang pancang yang dibebani lateral.

\subsection{RUANG LINGKUP PENELITIAN}

Ruang Lingkup yang menjadi batasan pada penelitian ini adalah sebagai berikut:

1. Tiang pancang yang dianalisis adalah tiang pancang beton dengan kepala tiang bebas (free head).

2. Bentuk penampang melintang (cross section) dari tiang pancang yang akan dianalisis adalah bentuk lingkaran dengan diameter, $\mathrm{d}=0.35 \mathrm{~m}$ dan bentuk persegi dengan sisi, $\mathrm{B}=0.35 \mathrm{~m}(0.35 \mathrm{~m} \times 0.35 \mathrm{~m})$.

3. Kedalaman pemancangan tiang, L yang ditinjau berturut-turut adalah 7, 10, dan 15 meter.

4. Lapisan tanah yang dianalisis adalah tanah non-kohesif; loose sand, medium sand dan dense sand.

5. Beban lateral bekerja di permukaan tanah.

6. Analisis kapasitas lateral dan defleksi lateral tiang pancang pada penelitian ini menggunakan metode Broms dan software Allpile.

Penempatan posisi beban lateral yang bekerja pada tiang serta dimensi tiang yang akan dianalisis pada penelitian ini tampak pada Gambar 1 .

Pengaruh Bentuk dan Rasio Kelangsingan Pada Tiang Pancang Yang Dibebani Lateral 

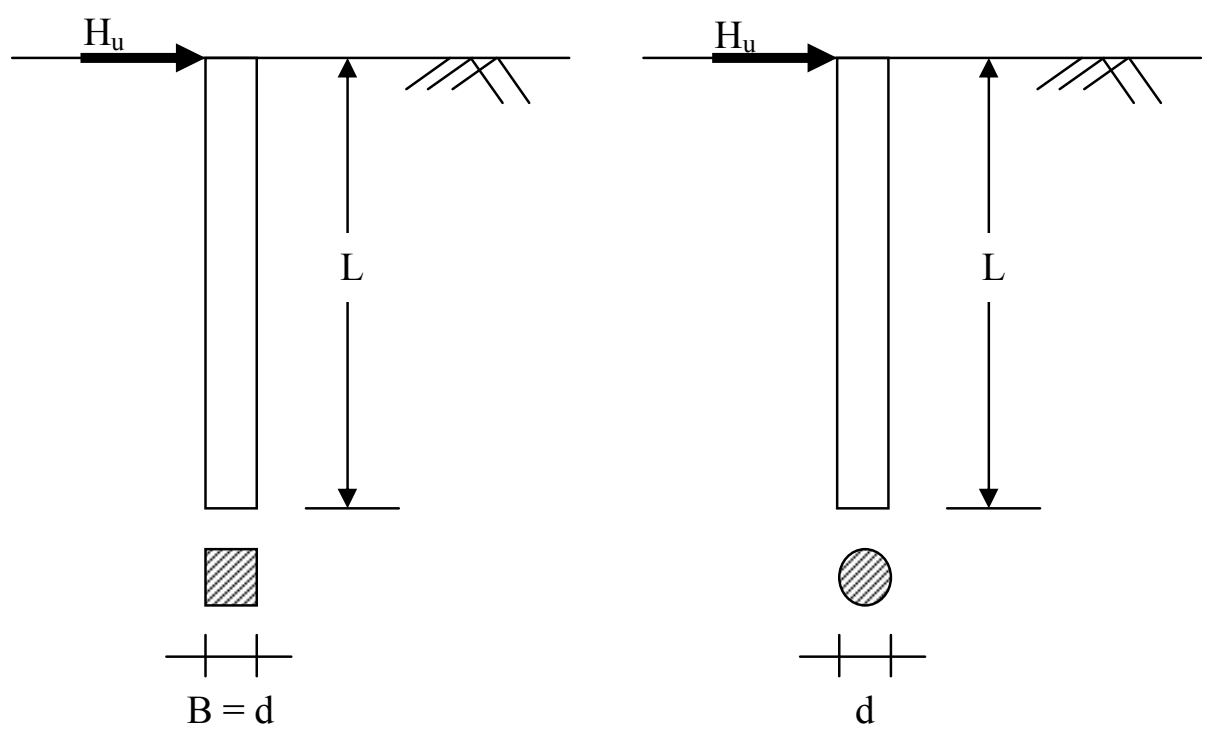

Gambar 1. Penempatan posisi beban lateral yang bekerja dan bentuk penampang melintang tiang pancang beton (a) tiang bentuk persegi (b) tiang bentuk lingkaran

\section{DATA TANAH DAN SPESIFIKASI TIANG}

Pada penelitian ini tiang pancang beton dimodelkan dipancang pada jenis tanah non-kohesif yaitu pasir (sand) homogen. Data tanah seperti compactness, nilai N-SPT, sudut geser dalam $(\phi)$, berat volume tanah $(\gamma)$, dan constant of horizontal subgrade reaction $\left(\eta_{h}\right)$ tampak pada Tabel 1.

Tabel 1. Data Tanah

\begin{tabular}{lccc}
\hline & Tanah 1 & Tanah 2 & Tanah 3 \\
\hline Compactness & Loose Sand & Medium Sand & Dense Sand \\
N-SPT & 6 & 20 & 45 \\
$\varphi\left(^{\circ}\right)$ & 28 & 33 & 39.8 \\
$\gamma\left(\mathrm{kN} / \mathrm{m}^{3}\right)$ & 17 & 18.9 & 20.8 \\
$\eta_{\mathrm{h}}\left(\mathrm{MN} / \mathrm{m}^{3}\right)$ & 2.5 & 7.5 & 20 \\
\hline
\end{tabular}

Tiang pancang yang digunakan pada penelitian ini adalah tiang pancang beton dengan bentuk persegi dan bentuk lingkaran. Pada pembahasan selanjutnya tiang pancang beton dengan bentuk persegi akan disebut tiang persegi dan tiang pancang beton dengan bentuk lingkaran selanjutnya akan disebut tiang lingkaran. 
Data tiang yang digunakan pada penelitian ini tampak pada Tabel 2. Tiang lingkaran dan tiang persegi akan dianalisis pada pemancangan tiang di tanah loose sand, medium sand, dan dense sand.

Tabel 2. Data Tiang

\begin{tabular}{lccc}
\hline & Tiang 1 & Tiang 2 & Tiang 3 \\
\hline Panjang Tiang, L (m) & 7.0 & 10.0 & 15.0 \\
Lebar/Diameter, d (m) & 0.35 & 0.35 & 0.35 \\
Rasio kelangsingan, L/d & 20.00 & 28.57 & 42.86 \\
Modulus Elatisitas & 23500 & 23500 & 23500 \\
$\begin{array}{l}\text { Tiang, } \mathrm{E}_{\mathrm{p}}(\mathrm{MPa}) \\
\text { Tegangan leleh baja }\end{array}$ & 400 & 400 & 400 \\
$\begin{array}{l}\text { tulangan, fy (MPa) } \\
\text { Kuat tekan beton, }\end{array}$ & 25 & 25 & 25 \\
fc' (MPa) & & & \\
\hline
\end{tabular}

\section{METODA BROMS}

Pada metoda ini digunakan diagram tegangan tanah yang disederhanakan dengan anggapan bahwa sepanjang kedalaman tiang reaksi atau tanahan tanah mencapai nilai ultimit.

\subsection{PENENTUAN KRITERIA TIANG PENDEK (SHORT PILE) DAN TIANG PANJANG (LONG PILE)}

Kriteria penentuan tiang pendek dan tiang panjang didasarkan pada kekakuan relatif antara pondasi tiang dengan tanah.

Faktor kekakuan $\mathrm{R}$ untuk menentukan perilaku tiang adalah sebagai berikut :

$$
R=\sqrt[4]{\frac{E_{p} \cdot I_{p}}{k_{s} \cdot B}}
$$

dimana :

$$
\begin{array}{ll}
\mathrm{E}_{\mathrm{p}} & =\text { modulus elastisitas tiang }\left(\text { ton } / \mathrm{m}^{2}\right) \\
\mathrm{I}_{\mathrm{p}} & =\text { momen inersia tiang }\left(\mathrm{m}^{4}\right) \\
\mathrm{k}_{\mathrm{s}} & =\text { modulus subgrade tanah dalam arah horizontal }\left(\text { ton } / \mathrm{m}^{3}\right)=\mathrm{k}_{1} / 1.5 \\
\mathrm{k}_{1} & =\text { modulus subgrade tanah }
\end{array}
$$




$$
\text { B } \quad=\mathrm{d}=\text { diameter atau lebar sisi tiang }(\mathrm{m})
$$

Faktor kekakuan $\mathrm{T}$ adalah sebagai berikut :

$$
T=\sqrt[5]{\frac{E_{p} \cdot I_{p}}{\eta_{h}}}
$$

dimana :

$\eta_{\mathrm{h}} \quad=$ constant of horizontal subgrade reaction (Tabel 3)

Modulus subgrade horizontal, $\mathrm{k}_{\mathrm{s}}$, dinyatakan sebagai berikut :

$$
k_{s}=\frac{\eta_{h} \cdot x}{B}
$$

dimana :

$$
\mathrm{x} \quad=\text { kedalaman yang ditinjau }
$$

Tabel 3. Nilai $\eta_{\mathrm{h}}$ untuk tanah non-kohesif

\begin{tabular}{lcccc}
\hline \multicolumn{1}{c}{ Relative density } & Loose & Medium & Dense \\
\hline $\begin{array}{l}\eta_{\mathrm{h}} \text { untuk dry atau moist soil } \\
\left(\mathrm{MN} / \mathrm{m}^{3}\right)\end{array}$ & 2.5 & 7.5 & 20 \\
$\begin{array}{l}\text { Terzaghi) } \\
\eta_{\mathrm{h}} \text { untuk submerged soil }\end{array}$ & $\left(\mathrm{MN} / \mathrm{m}^{3}\right)$ & 1.4 & 5 & 12 \\
$\begin{array}{l}\text { (Terzaghi) } \\
\eta_{\mathrm{h}} \text { untuk submerged soil } \\
\text { (Reese, dkk) }\end{array}$ & $\left(\mathrm{MN} / \mathrm{m}^{3}\right)$ & 5.3 & 16.3 & 34 \\
\hline
\end{tabular}

Kriteria tiang pendek atau panjang ditentukan berdasarkan nilai $\mathrm{R}$ atau $\mathrm{T}$ seperti tampak pada Tabel 4.

Tabel 4. Kriteria jenis perilaku tiang (Broms, 1964)

\begin{tabular}{ccc}
\hline Jenis perilaku tiang & \multicolumn{2}{c}{ Kriteria } \\
\hline Pendek (kaku) & $\mathrm{L} \leq 2 \mathrm{~T}$ & $\mathrm{~L} \leq 2 \mathrm{R}$ \\
Panjang (elastis) & $\mathrm{L} \geq 4 \mathrm{~T}$ & $\mathrm{~L} \geq 3.5 \mathrm{R}$ \\
\hline
\end{tabular}




\subsection{TIANG PANJANG DENGAN KEPALA TIANG BEBAS (FREE HEAD) PADA TANAH NON-KOHESIF}

Mekanisme keruntuhan, distribusi tahanan tanah dan momen lentur untuk tiang panjang dengan kepala tiang bebas pada tanah non-kohesif tampak pada Gambar 2. Kapasitas lateral tiang ultimit, $\mathrm{H}_{\mathrm{u}}$ dan momen maksimum, $\mathrm{M}_{\max }$ dinyatakan sebagai berikut :

$$
\begin{aligned}
& \mathrm{M}_{\max }=\mathrm{H}_{\mathrm{u}}\left(\mathrm{e}+0.67 \mathrm{x}_{0}\right) 0.82\left(\frac{H_{u}}{\gamma^{\prime} B K_{p}}\right)^{0.5} \\
& H_{u}=\frac{M_{u}}{e+0.54\left(\frac{H_{u}}{\gamma^{\prime} B K_{p}}\right)^{0,5}}
\end{aligned}
$$

dimana :

$$
\begin{array}{ll}
\mathrm{M}_{\mathrm{u}} & =\text { kapasitas momen ultimit dari penampang tiang } \\
\mathrm{e} & =\text { jarak dari } \mathrm{H}_{\mathrm{u}} \text { ke permukaan tanah } \\
\mathrm{K}_{\mathrm{p}} & =(1+\sin \phi) /(1-\sin \phi) \\
\gamma^{\prime} & =\text { berat volume tanah efektif }
\end{array}
$$

Nilai $\mathrm{H}_{\mathrm{u}}$ dapat dihitung dengan menggunakan diagram yang menyatakan hubungan antara nilai $\mathrm{H}_{\mathrm{u}} /\left(\mathrm{K}_{\mathrm{p}} \gamma^{\prime} \mathrm{B}^{3}\right)$ dan nilai $\mathrm{M}_{\mathrm{u}} /\left(\mathrm{K}_{\mathrm{p}} \gamma^{\prime} \mathrm{B}^{4}\right)$ seperti tampak pada Gambar 3. 


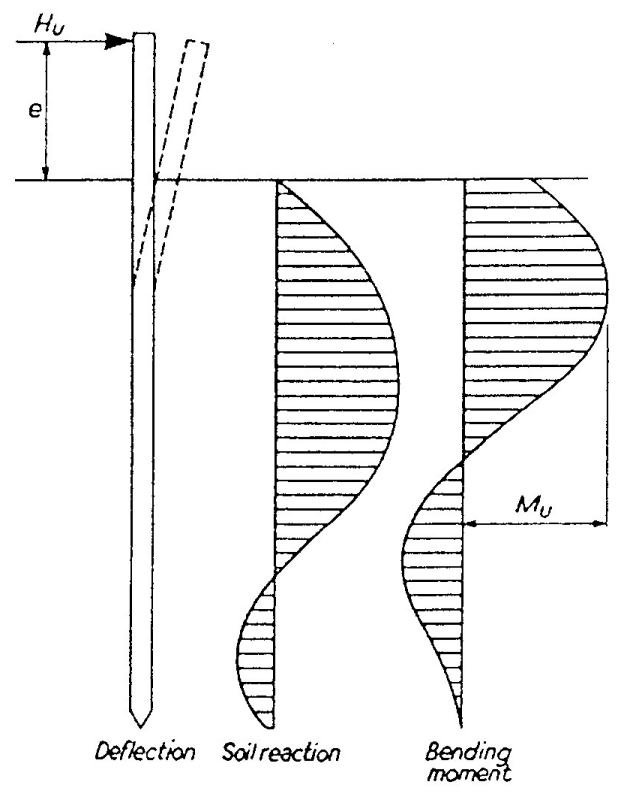

Gambar 2. Perlawanan tanah dan momen lentur pada tiang panjang dengan kepala tiang bebas pada tanah non kohesif (Broms, 1964)

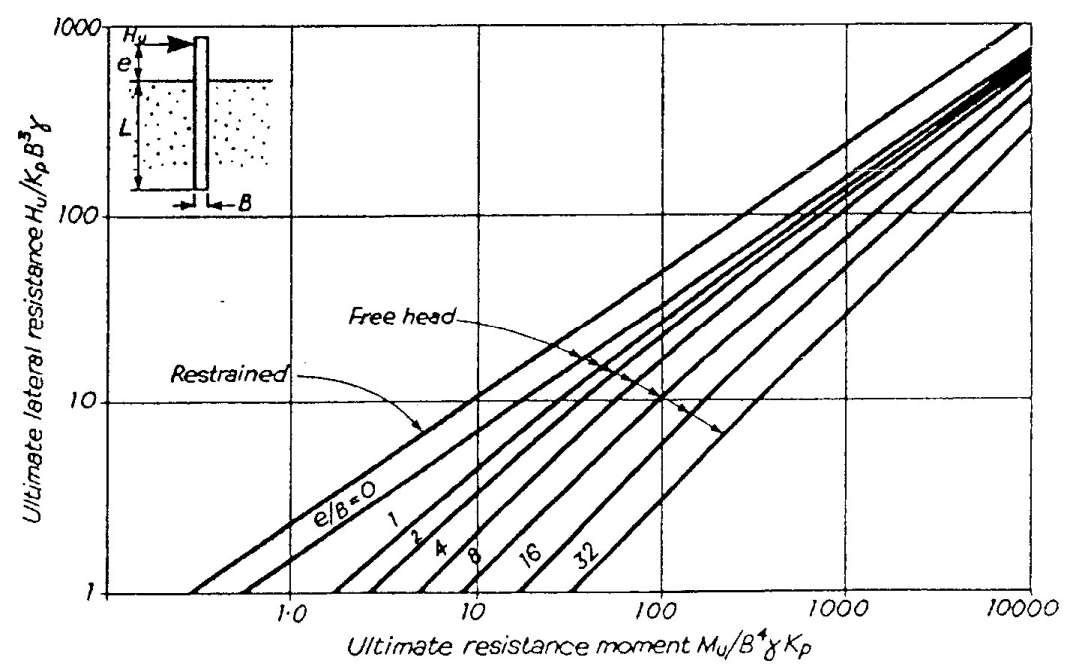

Gambar 3. Kapasitas lateral ultimit untuk tiang panjang pada tanah non-kohesif

(Broms, 1964)

\subsection{TIANG PANJANG DENGAN KEPALA TIANG TERJEPIT (FIXED HEAD) PADA TANAH NON-KOHESIF}

Mekanisme keruntuhan, distribusi tahanan tanah dan momen lentur untuk tiang panjang dengan kepala tiang terjepit pada non-kohesif tampak pada Gambar 4. 


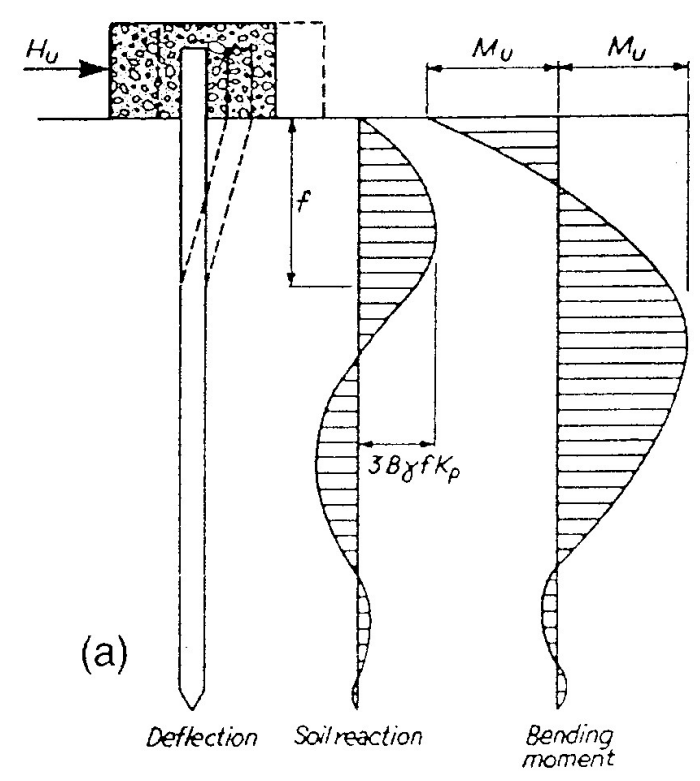

Gambar 4. Perlawanan tanah dan momen lentur tiang panjang dengan kondisi kepala tiang terjepit pada tanah non-kohesif (Broms, 1964)

Kapasitas lateral tiang, $H_{u}$ dan momen maksimum, $M_{\max }$ dinyatakan sebagai berikut :

$$
\begin{aligned}
& H_{u}=\frac{2 M_{u}}{\left(e+0.67 x_{0}\right)} \\
& x_{0}=0.82\left(\frac{H_{u}}{\gamma^{\prime} B K_{p}}\right)^{0.5} \\
& \mathrm{M}_{\max }=\mathrm{H}_{\mathrm{u}}\left(\mathrm{e}+0.67 \mathrm{x}_{0}\right)
\end{aligned}
$$

Kapasitas lateral ultimit untuk tiang dapat diperoleh dari Gambar 3.

\section{HASIL ANALISIS}

Hasil analisis kriteria tiang untuk tiang lingkaran yang digunakan pada penelitian ini ditunjukkan pada Tabel 5 hingga Tabel 7, sementara untuk tiang persegi ditunjukkan pada Tabel 8 hingga Tabel 10. 
Tabel 5. Hasil analisis kriteria tiang untuk tiang lingkaran pada tanah loose sand

\begin{tabular}{ccccc}
\hline Tiang & $\mathrm{L}(\mathrm{m})$ & $\mathrm{d}(\mathrm{m})$ & $\mathrm{L} / \mathrm{T}$ & Kriteria Tiang \\
\hline 1 & 15.0 & 0.35 & $4.754>4$ & Tiang Panjang \\
2 & 10.0 & 0.35 & $6.791>4$ & Tiang Panjang \\
3 & 7.0 & 0.35 & $10.186>4$ & Tiang Panjang \\
\hline
\end{tabular}

Tabel 6. Hasil analisis kriteria tiang untuk tiang lingkaran pada tanah medium sand

\begin{tabular}{ccccc}
\hline Tiang & $\mathrm{L}(\mathrm{m})$ & $\mathrm{d}(\mathrm{m})$ & $\mathrm{L} / \mathrm{T}$ & Kriteria Tiang \\
\hline 1 & 15.0 & 0.35 & $5.922>4$ & Tiang Panjang \\
2 & 10.0 & 0.35 & $8.460>4$ & Tiang Panjang \\
3 & 7.0 & 0.35 & $12.869>4$ & Tiang Panjang \\
\hline
\end{tabular}

Tabel 7. Hasil analisis kriteria tiang untuk tiang lingkaran pada tanah medium sand

\begin{tabular}{cllcl}
\hline Tiang & $\mathrm{L}(\mathrm{m})$ & $\mathrm{d}(\mathrm{m})$ & $\mathrm{L} / \mathrm{T}$ & Kriteria Tiang \\
\hline 1 & 15.0 & 0.35 & $7.205>4$ & Tiang Panjang \\
2 & 10.0 & 0.35 & $10.293>4$ & Tiang Panjang \\
3 & 7.0 & 0.35 & $15.440>4$ & Tiang Panjang \\
\hline
\end{tabular}

Tabel 8. Hasil analisis kriteria tiang untuk tiang persegi pada tanah loose sand

\begin{tabular}{cllcl}
\hline Tiang & L $(\mathrm{m})$ & $\mathrm{d}(\mathrm{m})$ & $\mathrm{L} / \mathrm{T}$ & Kriteria Tiang \\
\hline 1 & 15.0 & 0.35 & $4.276>4$ & Tiang Panjang \\
2 & 10.0 & 0.35 & $6.109>4$ & Tiang Panjang \\
3 & 7.0 & 0.35 & $9.163>4$ & Tiang Panjang \\
\hline
\end{tabular}

Tabel 9. Hasil analisis kriteria tiang untuk tiang persegi pada tanah medium sand

\begin{tabular}{ccccc}
\hline \multirow{2}{*}{ Tiang } & L $(\mathrm{m})$ & $\mathrm{d}(\mathrm{m})$ & $\mathrm{L} / \mathrm{T}$ & Kriteria Tiang \\
\hline 1 & 15.0 & 0.35 & $5.327>4$ & Tiang Panjang \\
2 & 10.0 & 0.35 & $7.610>4$ & Tiang Panjang \\
3 & 7.0 & 0.35 & $11.415>4$ & Tiang Panjang \\
\hline
\end{tabular}


Tabel 10. Hasil analisis kriteria tiang untuk tiang persegi pada tanah dense sand

\begin{tabular}{ccccc}
\hline Tiang & L $(\mathrm{m})$ & $\mathrm{d}(\mathrm{m})$ & $\mathrm{L} / \mathrm{T}$ & Kriteria Tiang \\
\hline 1 & 15.0 & 0.35 & $6.481>4$ & Tiang Panjang \\
2 & 10.0 & 0.35 & $9.259>4$ & Tiang Panjang \\
3 & 7.0 & 0.35 & $13.889>4$ & Tiang Panjang \\
\hline
\end{tabular}

Hasil analisis dengan metoda Broms untuk tiang lingkaran yang dipancang pada tanah loose sand, medium sand dan dense sand menunjukkan bahwa perubahan rasio kelangsingan, L/d dengan kondisi dimana diameter tiang, $\mathrm{d}$ tetap dan kedalaman tiang, $\mathrm{L}$ bertambah, menghasilkan kapasitas lateral tiang ultimit, $\mathrm{H}_{\mathrm{u}}$ yang konstan, hasil analisis ditunjukkan pada Tabel 11 hingga Tabel 13.

Defleksi lateral pada kepala tiang (pile head) dianalisis dengan metoda Broms dan software Allpile. Kurva hubungan antara rasio kelangsingan, L/d dan defleksi lateral pada tiang lingkaran kondisi kapasitas lateral tiang ultimit pada tanah loose sand, medium sand dan dense sand ditunjukkan pada Gambar 5 hingga Gambar 7.

Tabel 11. Kapasitas lateral tiang ultimit dan defleksi lateral untuk tiang lingkaran pada

\begin{tabular}{ccccccc}
\multicolumn{7}{c}{ tanah loose sand } \\
\hline \multirow{2}{*}{ Tiang } & $\mathrm{L}(\mathrm{m})$ & $\mathrm{d}(\mathrm{m})$ & $\mathrm{L} / \mathrm{d}$ & $\begin{array}{c}\text { Kapasitas lateral tiang } \\
\text { ultimit, } \mathrm{H}_{\mathrm{u}}(\mathrm{kN})\end{array}$ & Defleksi lateral $(\mathrm{mm})$ \\
\cline { 5 - 7 } & & & & Broms & Allpile & Broms \\
\hline 1 & 15.0 & 0.35 & 42.86 & 66.81 & 23.00 & 35.38 \\
2 & 10.0 & 0.35 & 28.57 & 66.81 & 23.00 & 34.24 \\
3 & 7.0 & 0.35 & 20.00 & 66.81 & 23.00 & 31.95 \\
\hline
\end{tabular}




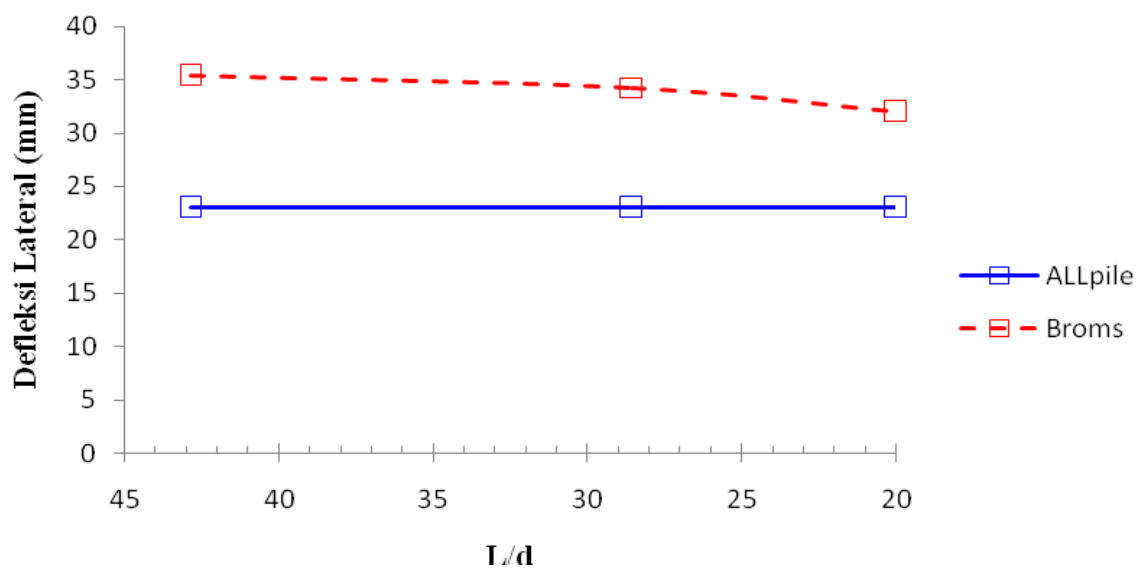

Gambar 5. L/d vs Defleksi Lateral antara metoda Broms dan Allpile untuk tiang lingkaran pada tanah loose sand

Tabel 12. Kapasitas lateral tiang ultimit dan defleksi lateral untuk tiang lingkaran pada tanah medium sand

\begin{tabular}{|c|c|c|c|c|c|c|}
\hline \multirow{2}{*}{ Tiang } & \multirow{2}{*}{$\mathrm{L}(\mathrm{m})$} & \multirow{2}{*}{$\mathrm{d}(\mathrm{m})$} & \multirow{2}{*}{$\mathrm{L} / \mathrm{d}$} & \multirow{2}{*}{$\begin{array}{c}\text { Kapasitas Dukung Lateral } \\
\text { Ultimit, } \mathrm{H}_{\mathrm{u}}(\mathrm{kN})\end{array}$} & \multicolumn{2}{|c|}{ Defleksi Lateral (mm) } \\
\hline & & & & & Allpile & Broms \\
\hline 1 & 15.0 & 0.35 & 42.86 & 92.43 & 24.00 & 23.16 \\
\hline 2 & 10.0 & 0.35 & 28.57 & 92.43 & 24.00 & 15.44 \\
\hline 3 & 7.0 & 0.35 & 20.00 & 92.43 & 24.00 & 14.41 \\
\hline
\end{tabular}

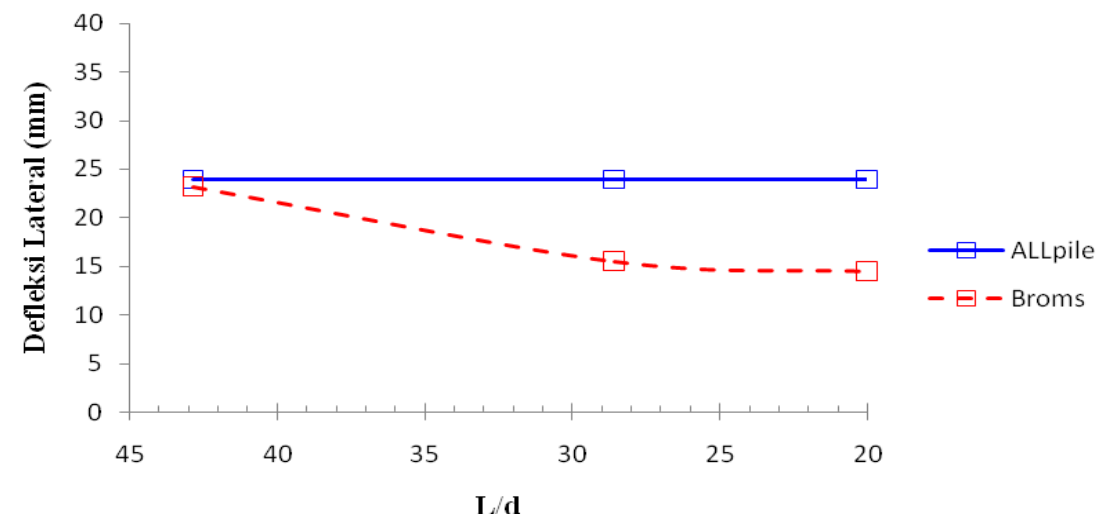

Gambar 6. L/d vs Defleksi Lateral antara metoda Broms dan Allpile untuk tiang lingkaran pada tanah medium sand 
Tabel 13. Kapasitas lateral tiang ultimit dan defleksi lateral untuk tiang lingkaran pada

\begin{tabular}{llllcll}
\multicolumn{7}{c}{ tanah dense sand } \\
\hline \multirow{2}{*}{ Tiang } & L $(\mathrm{m})$ & $\mathrm{d}(\mathrm{m})$ & $\mathrm{L} / \mathrm{d}$ & $\begin{array}{c}\text { Kapasitas Beban Lateral } \\
\text { Ultimit, } \mathrm{H}_{\mathrm{u}}(\mathrm{kN})\end{array}$ & Defleksi Lateral $(\mathrm{mm})$ \\
\cline { 5 - 7 } & & & & Broms & Allpile & Broms \\
\hline 1 & 15.0 & 0.35 & 42.86 & 106.44 & 17.00 & 18.01 \\
2 & 10.0 & 0.35 & 28.57 & 106.44 & 17.00 & 12.01 \\
3 & 7.0 & 0.35 & 20.00 & 106.44 & 17.00 & 11.21 \\
\hline
\end{tabular}

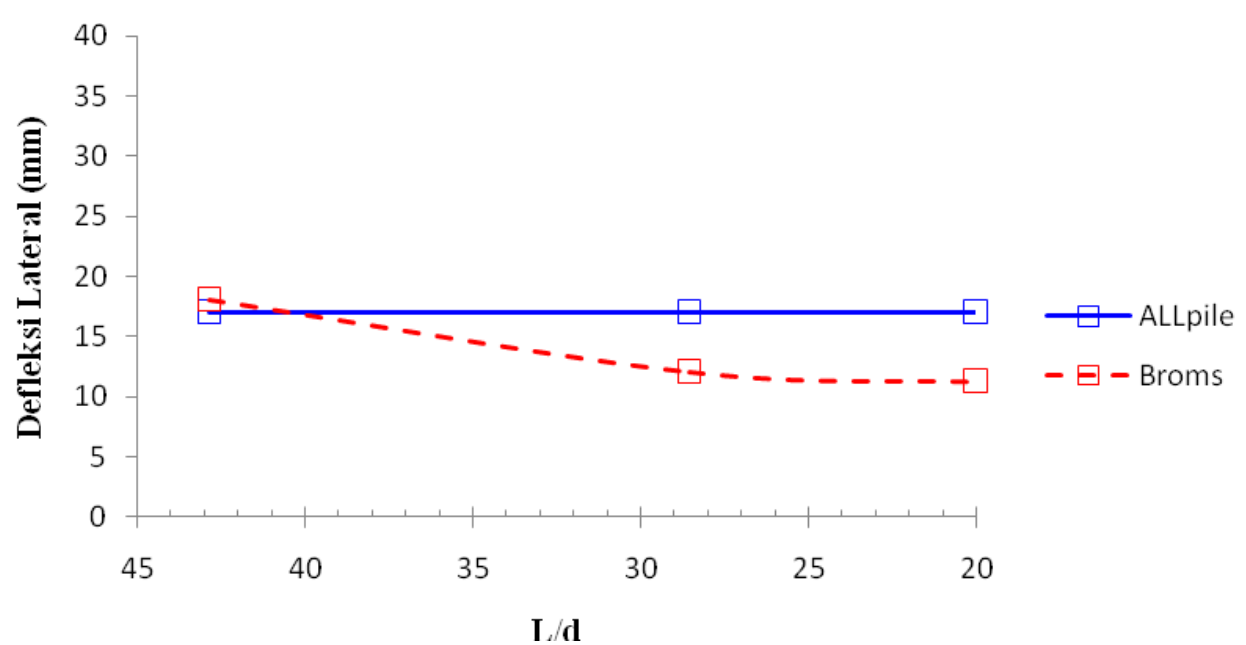

Gambar 7. L/d vs Defleksi Lateral antara metoda Broms dan Allpile untuk tiang lingkaran pada tanah dense sand

Hasil analisis dengan metoda Broms untuk tiang persegi yang dipancang pada tanah loose sand, medium sand dan dense sand menunjukkan bahwa perubahan rasio kelangsingan, $\mathrm{L} / \mathrm{d}$ dengan kondisi dimana diameter tiang, $\mathrm{d}$ tetap dan kedalaman tiang, $\mathrm{L}$ bertambah, menghasilkan kapasitas lateral tiang ultimit, $\mathrm{H}_{\mathrm{u}}$ yang konstan, hasil analisis ditunjukkan pada Tabel 14 hingga Tabel 16.

Defleksi lateral pada kepala tiang (pile head) dianalisis dengan metoda Broms dan software Allpile. Kurva hubungan antara rasio kelangsingan, L/d dan defleksi lateral tiang persegi pada kondisi kapasitas lateral tiang ultimit pada tanah loose sand, medium sand dan dense sand ditunjukkan pada Gambar 8 hingga Gambar 10. 
Tabel 14. Kapasitas lateral tiang ultimit dan defleksi lateral untuk tiang persegi pada

\begin{tabular}{llllcll}
\multicolumn{7}{c}{ tanah loose sand } \\
\hline \multirow{2}{*}{ Tiang } & $\mathrm{L}(\mathrm{m})$ & $\mathrm{d}(\mathrm{m})$ & $\mathrm{L} / \mathrm{d}$ & $\begin{array}{c}\text { Kapasitas Beban Lateral } \\
\text { Ultimit, } \mathrm{H}_{\mathrm{u}}(\mathrm{kN})\end{array}$ & Defleksi Lateral $(\mathrm{mm})$ \\
\cline { 5 - 7 } & & & & Broms & Allpile & Broms \\
\hline 1 & 15.0 & 0.35 & 42.86 & 81.09 & 22.00 & 35.27 \\
2 & 10.0 & 0.35 & 28.57 & 81.09 & 22.00 & 30.24 \\
3 & 7.0 & 0.35 & 20.00 & 81.09 & 22.00 & 28.21 \\
\hline
\end{tabular}

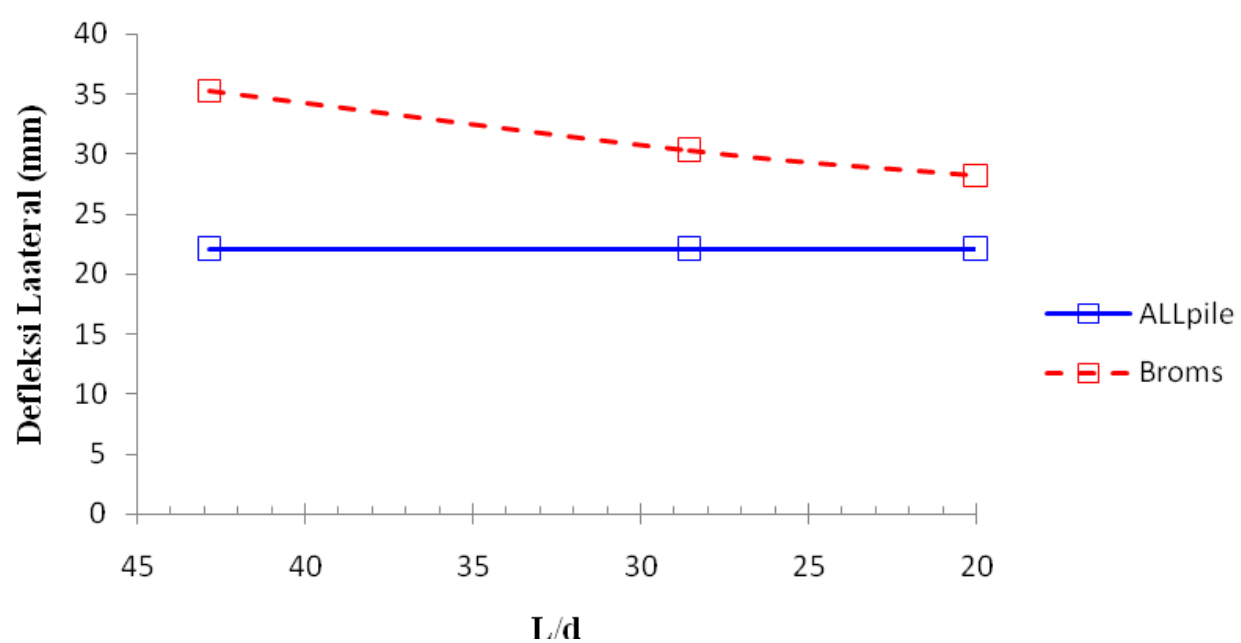

Gambar 8. L/d vs Defleksi Lateral antara metoda Broms dan Allpile untuk tiang persegi pada tanah loose sand

Tabel 15. Kapasitas lateral tiang ultimit dan defleksi lateral untuk tiang persegi pada tanah medium sand

\begin{tabular}{|c|c|c|c|c|c|c|}
\hline \multirow[t]{2}{*}{ Tiang } & \multirow[t]{2}{*}{$\mathrm{L}(\mathrm{m})$} & \multirow[t]{2}{*}{$\mathrm{d}(\mathrm{m})$} & \multirow[t]{2}{*}{$\mathrm{L} / \mathrm{d}$} & \multirow{2}{*}{$\begin{array}{c}\text { Kapasitas Beban Lateral } \\
\text { Ultimit, } \mathrm{H}_{\mathrm{u}}(\mathrm{kN})\end{array}$} & \multicolumn{2}{|c|}{ Defleksi Lateral (mm) } \\
\hline & & & & & Allpile & Broms \\
\hline 1 & 15.0 & 0.35 & 42.86 & 106.75 & 21.00 & 19.47 \\
\hline 2 & 10.0 & 0.35 & 28.57 & 106.75 & 21.00 & 18.17 \\
\hline 3 & 7.0 & 0.35 & 20.00 & 106.75 & 21.00 & 18.17 \\
\hline
\end{tabular}




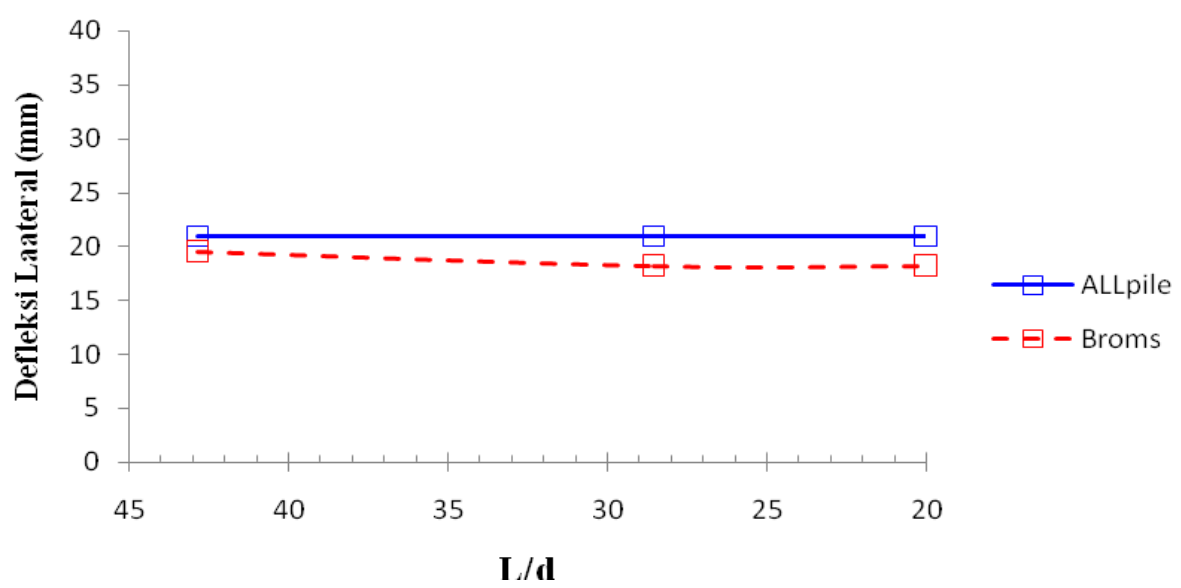

Gambar 9. L/d vs Defleksi Lateral antara metoda Broms dan Allpile untuk tiang persegi pada tanah medium sand

Tabel 16. Kapasitas lateral tiang ultimit dan defleksi lateral untuk tiang persegi pada tanah dense sand

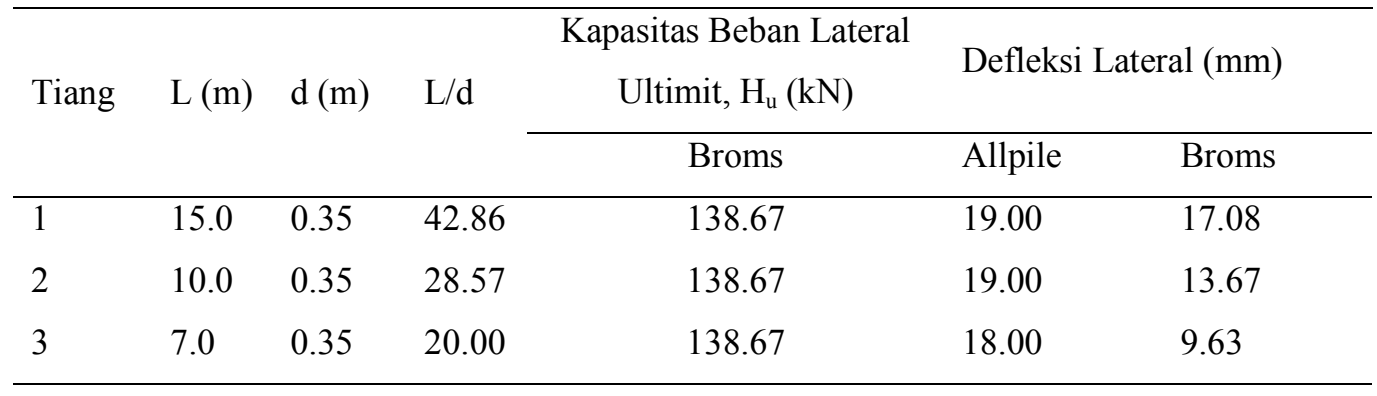

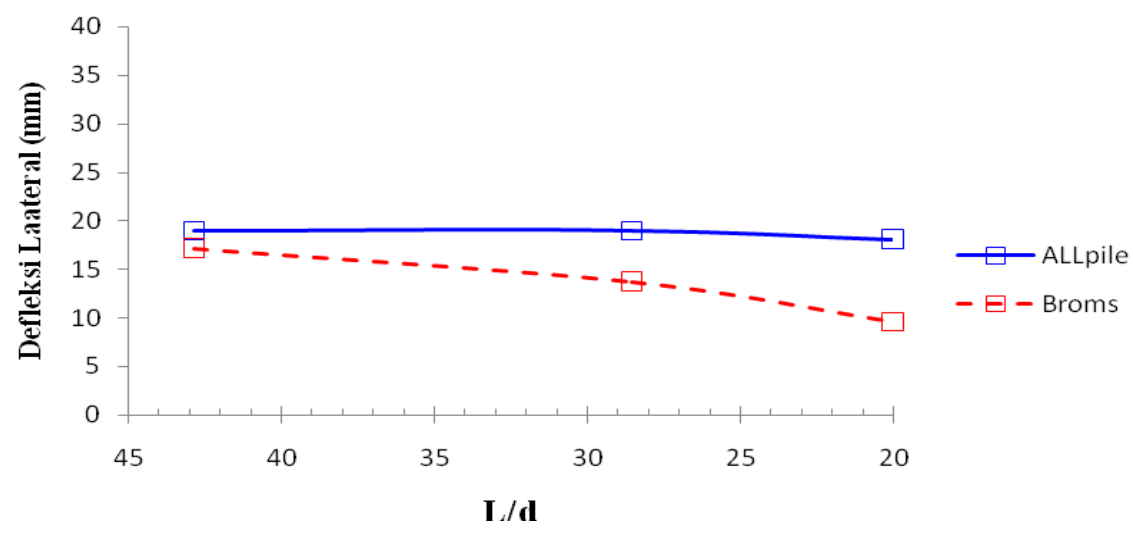

Gambar 10. L/d vs Defleksi Lateral antara metoda Broms dan Allpile untuk tiang persegi pada tanah dense sand 
Pada tiang lingkaran, peningkatan compactness pada tanah pasir akan menghasilkan peningkatan kapasitas lateral tiang ultimit dan memperkecil nilai defleksi lateral pada kepala tiang seperti ditunjukkan pada Tabel 17.

Tabel 17. Hasil analisis kapasitas lateral tiang ultimit dan defleksi lateral untuk tiang lingkaran

\begin{tabular}{ccccc}
\hline \multirow{2}{*}{ Tiang } & $\begin{array}{c}\text { Soil } \\
\text { Compactness }\end{array}$ & $\mathrm{L} / \mathrm{d}$ & $\begin{array}{c}\text { Kapasitas lateral tiang } \\
\text { ultimit, } \mathrm{H}_{\mathrm{u}}(\mathrm{kN})\end{array}$ & $\begin{array}{c}\text { Defleksi } \\
\text { Lateral }(\mathrm{mm})\end{array}$ \\
\cline { 3 - 5 } & & 42.86 & Broms & Broms \\
\hline 1 & Loose Sand & 28.57 & 66.81 & 35.38 \\
2 & 20.00 & 66.81 & 34.24 \\
3 & & 42.86 & 66.81 & 31.95 \\
\hline 1 & \multirow{2}{*}{ Medium Sand } & 28.57 & 92.43 & 23.16 \\
2 & & 20.00 & 92.43 & 15.44 \\
3 & & 42.86 & 92.43 & 14.41 \\
\hline 1 & & 106.44 & 18.01 \\
2 & Dense Sand & 28.57 & 106.44 & 12.01 \\
3 & & 20.00 & 106.44 & 11.21 \\
\hline
\end{tabular}

Penurunan nilai rasio kelangsingan, L/d akan memperkecil nilai defleksi lateral pada kepala tiang untuk tiang lingkaran seperti ditunjukkan pada Gambar 11.

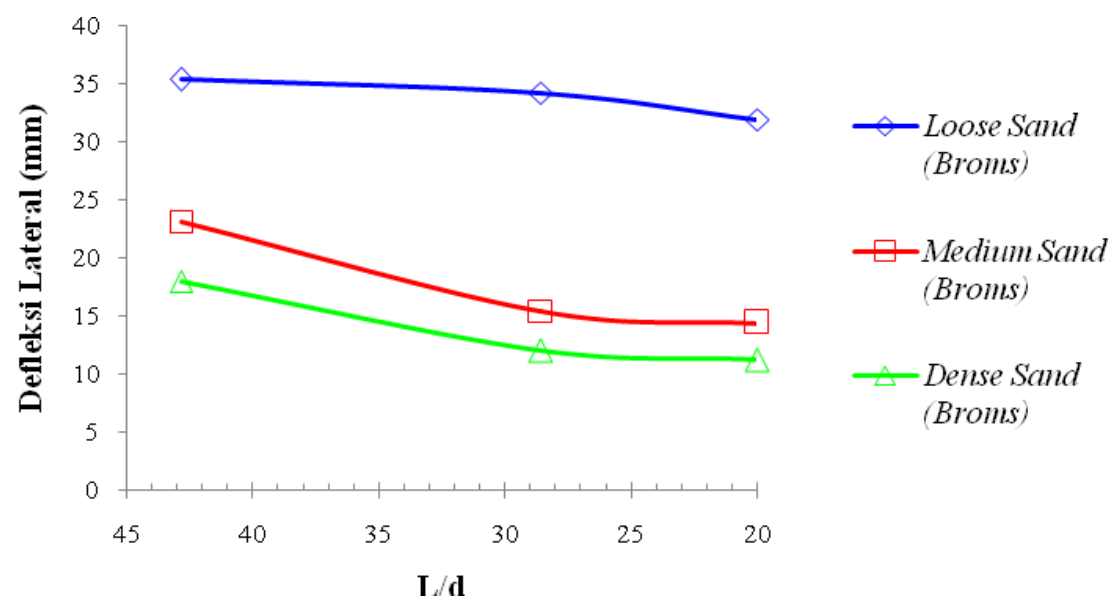

Gambar 11. L/d vs Defleksi Lateral tiang lingkaran 
Demikian juga halnya pada tiang persegi, peningkatan compactness pada tanah pasir akan menghasilkan peningkatan kapasitas lateral tiang ultimit dan memperkecil nilai defleksi lateral pada kepala tiang seperti ditunjukkan pada Tabel 18.

Tabel 18. Hasil analisis kapasitas lateral tiang ultimit dan defleksi lateral untuk tiang

\begin{tabular}{|c|c|c|c|c|}
\hline \multirow[t]{2}{*}{ Tiang } & \multirow[t]{2}{*}{$\begin{array}{c}\text { Soil } \\
\text { Compactness }\end{array}$} & \multirow[t]{2}{*}{$\mathrm{L} / \mathrm{d}$} & $\begin{array}{c}\text { Kapasitas lateral tiang } \\
\text { ultimit, } \mathrm{H} u(\mathrm{kN})\end{array}$ & $\begin{array}{c}\text { Defleksi } \\
\text { Lateral } \\
(\mathrm{mm})\end{array}$ \\
\hline & & & Broms & Broms \\
\hline 1 & & 42.86 & 81.09 & 35.27 \\
\hline 2 & Loose Sand & 28.57 & 81.09 & 30.24 \\
\hline 3 & & 20.00 & 81.09 & 28.21 \\
\hline 1 & & 42.86 & 106.75 & 19.47 \\
\hline 2 & Medium Sand & 28.57 & 106.75 & 18.17 \\
\hline 3 & & 20.00 & 106.75 & 18.17 \\
\hline 1 & & 42.86 & 138.67 & 17.08 \\
\hline 2 & Dense Sand & 28.57 & 138.67 & 13.67 \\
\hline 3 & & 20.00 & 138.67 & 9.63 \\
\hline
\end{tabular}

Penurunan nilai rasio kelangsingan, L/d akan memperkecil nilai defleksi lateral pada kepala tiang untuk tiang lingkaran seperti ditunjukkan pada Gambar 12.

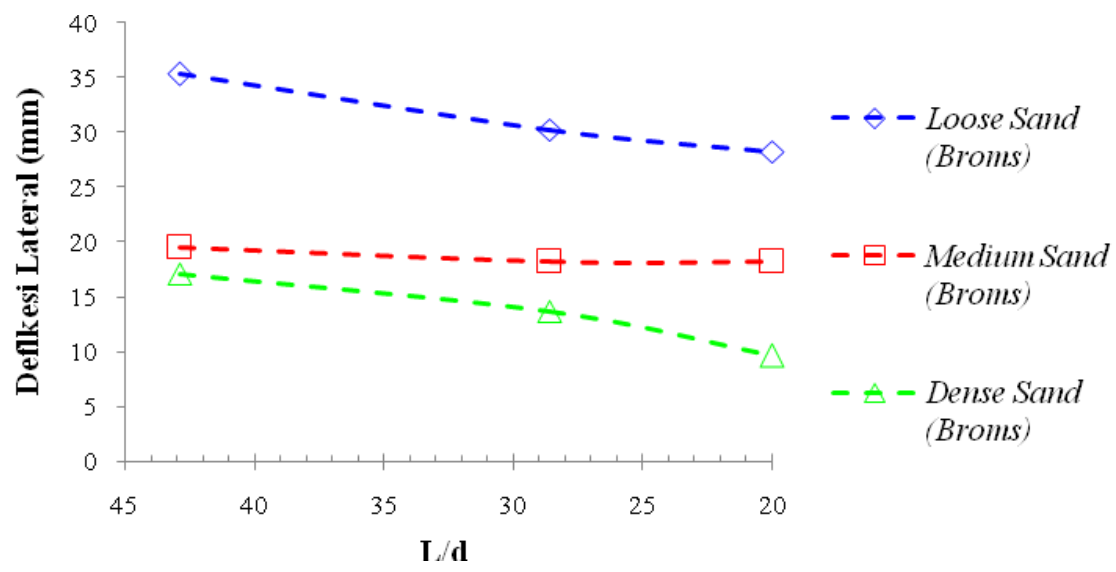

Gambar 12. L/d vs Defleksi Lateral tiang persegi 
Tiang persegi menghasilkan kapasitas lateral tiang ultimit yang lebih besar jika dibandingkan dengan tiang lingkaran, baik saat pemancangan pada tanah loose sand, medium sand maupun dense sand seperti ditunjukkan apada Tabel 19.

Tabel 19. Perbandingan bentuk tiang terhadap kapasitas lateral tiang ultimit

\begin{tabular}{cccc}
\hline \multirow{2}{*}{ Jenis Tanah } & \multicolumn{2}{c}{ Kapasitas lateral tiang ultimit, $\mathrm{H}_{\mathrm{u}}(\mathrm{kN})$} & Perbandingan \\
\cline { 2 - 3 } & Tiang Persegi & Tiang Lingkaran & $(\%)$ \\
\cline { 2 - 3 } & Broms & Broms & 17.61 \\
\hline Loose sand & 81.09 & 66.81 & 13.41 \\
Medium sand & 106.75 & 92.43 & 23.24 \\
Dense sand & 138.67 & 106.44 & \\
\hline
\end{tabular}

Hasil analisis dengan menggunakan software Allpile seperti tampak pada Gambar 13 menunjukkan bahwa baik untuk tiang persegi maupun tiang lingkaran yang dipancang pada tanah loose sand, medium sand dan dense sand, perubahan rasio kelangsingan, L/d dengan kondisi dimana diameter tiang, d tetap dan kedalaman tiang, L bertambah, menghasilkan kapasitas lateral tiang yang konstan. Selain itu hasil analisis pun menunjukkan bahwa tiang persegi menghasilkan kapasistas lateral tiang yang lebih besar jika dibandingkan dengan tiang lingkaran. 


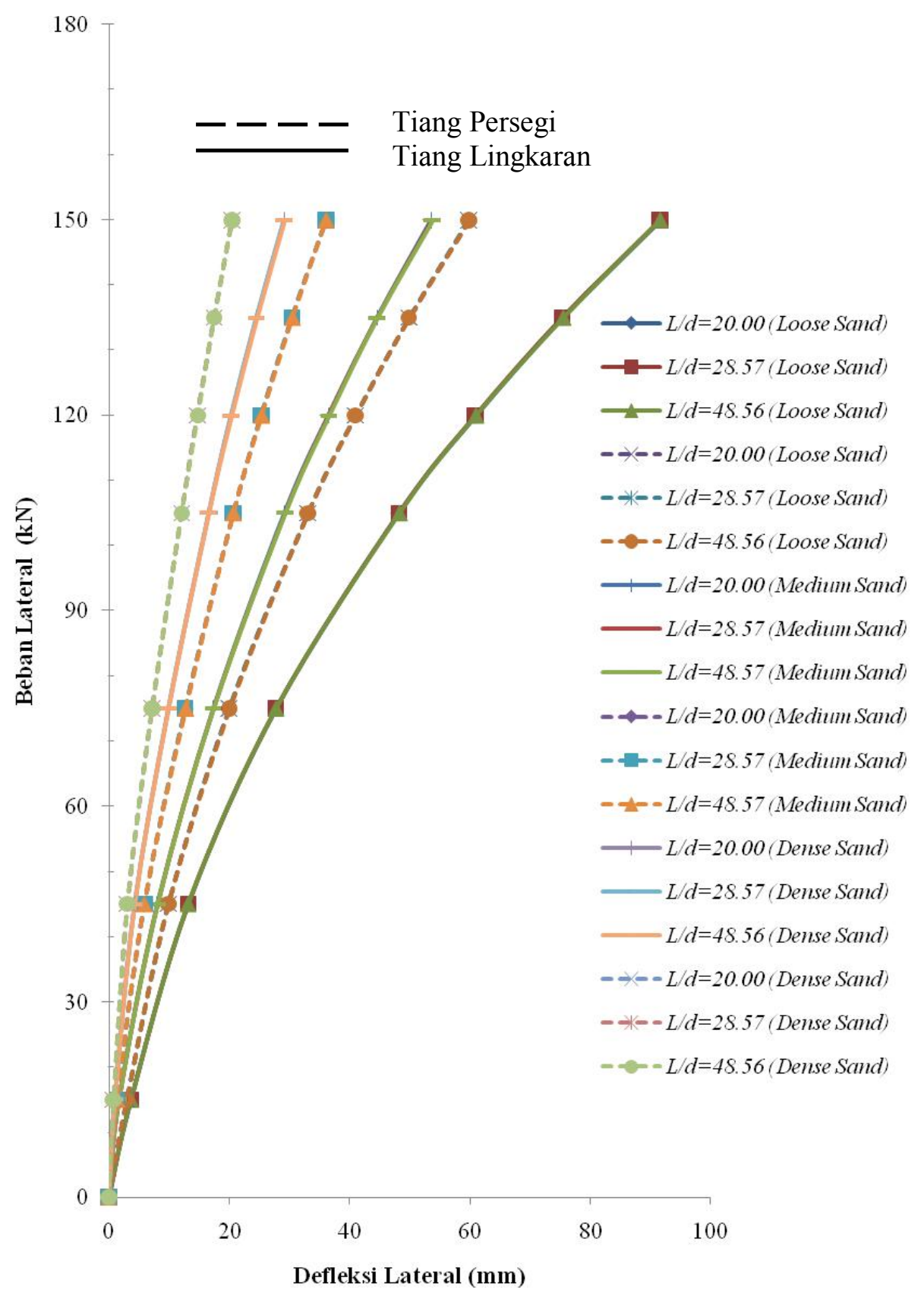

Gambar 13. Defleksi Lateral vs Beban Lateral untuk tiang persegi dan tiang lingkaran pada tanah non-kohesif 


\section{SIMPULAN}

Simpulan dari hasil penelitian yang telah dilakukan antara lain adalah :

1. Kapasitas lateral tiang pancang beton berbentuk persegi lebih besar jika dibandingkan dengan tiang pancang beton berbentuk lingkaran.

2. Persentase perbedaan kapasitas lateral tiang pancang dengan bentuk persegi dibandingkan dengan bentuk lingkaran berturut-turut adalah ; $17.61 \%$ untuk kondisi pemancangan pada tanah loose sand, $13.41 \%$ untuk kondisi pemancangan pada tanah medium sand, $23.24 \%$ untuk kondisi pemancangan pada tanah dense sand.

3. Perubahan nilai rasio kelangsingan, $L / d$ tidak mempengaruhi besarnya kapasitas lateral tiang pancang baik untuk tiang persegi maupun tiang lingkaran.

4. Penurunan nilai rasio kelangsingan, $\mathrm{L} / \mathrm{d}$ akan memperkecil nilai defleksi lateral pada kepala tiang baik untuk tiang persegi maupun untuk tiang lingkaran.

\section{DAFTAR PUSTAKA}

1. Geotechnical Engineering Center, (2005). Manual Pondasi Tiang, Edisi 3, Unpar.

2. Jeyalakshmi, P., Vineetha, J., (2014). Behavior of Laterally Loaded Piles in Cohesive Soil, International Journal of Research in Engineering and Technology, Volume 03, eISN: 2319-1163 pISSN: 2321-7308, NECHAMESE

3. Poulos, H.G., Davis, E.H., (1980). Pile Foundation Analysis and Design, John Wiley \& Sons, Canada.

4. Prakash, S., Sharma, H.D., (1990). Pile Foundation in Engineering Practice, John Wiley \& Sons.

5. SNI 03-4434-1997, Spesifikasi Tiang Pancang Beton Pracetak untuk Pondasi Jembatan, Ukuran $(30 \times 30,35 \times 35,40 \times 40) \mathrm{cm} 2$ Panjang 10-20 meter dengan Baja Tulangan BJ 24 dan BJ 40, Pustran - Balitbang PU.

6. Sudalaimani, A., Gomathi, M., Vineetha, J., (2014). Response of Laterally Loaded Single Pile in Sandy Soil, International Journal of Research in Engineering and Technology, Volume 03, eISN: 2319-1163 pISSN: 2321-7308, NECHAMESE 